\title{
Novel approach to characterising individuals with low back-related leg pain: cluster identification with latent class analysis and 12-month follow-up
}

Siobhán Stynes*, Kika Konstantinou, Reuben Ogollah, Elaine M. Hay, Kate M. Dunn

\begin{abstract}
Traditionally, low back-related leg pain (LBLP) is diagnosed clinically as referred leg pain or sciatica (nerve root involvement). However, within the spectrum of LBLP, we hypothesised that there may be other unrecognised patient subgroups. This study aimed to identify clusters of patients with LBLP using latent class analysis and describe their clinical course. The study population was 609 LBLP primary care consulters. Variables from clinical assessment were included in the latent class analysis. Characteristics of the statistically identified clusters were compared, and their clinical course over 1 year was described. A 5 cluster solution was optimal. Cluster $1(n=104)$ had mild leg pain severity and was considered to represent a referred leg pain group with no clinical signs, suggesting nerve root involvement (sciatica). Cluster $2(n=122)$, cluster $3(n=188)$, and cluster $4(n=69)$ had mild, moderate, and severe pain and disability, respectively, and response to clinical assessment items suggested categories of mild, moderate, and severe sciatica. Cluster $5(n=126)$ had high pain and disability, longer pain duration, and more comorbidities and was difficult to map to a clinical diagnosis. Most improvement for pain and disability was seen in the first 4 months for all clusters. At 12 months, the proportion of patients reporting recovery ranged from $27 \%$ for cluster 5 to $45 \%$ for cluster 2 (mild sciatica). This is the first study that empirically shows the variability in profile and clinical course of patients with LBLP including sciatica. More homogenous groups were identified, which could be considered in future clinical and research settings.
\end{abstract}

Keywords: Sciatica, Low back-related leg pain, Latent class analysis, Primary care, Clinical course

\section{Background}

Trials evaluating treatments for low back pain (LBP) show at best moderate effect sizes. ${ }^{11}$ The heterogeneity of patients with LBP within studies is 1 explanation for these results. This has stimulated research aiming to identify more homogeneous, clinically relevant subgroups of patients with LBP, with the hope that these subgroups might respond more favourably to interventions or management approaches matched to the subgroup's characteristics or presenting symptoms. ${ }^{12,36}$

One of the most common subgroup of LBP is back pain radiating to the leg, which represents about two-thirds of patients with back

Sponsorships or competing interests that may be relevant to content are disclosed at the end of this article.

Arthritis Research UK Primary Care Centre, Research Institute for Primary Care and Health Sciences, Keele University, Keele, United Kingdom

${ }^{*}$ Corresponding author. Address: Arthritis Research UK Primary Care Centre, Research Institute for Primary Care and Health Sciences, Keele University, Keele, Staffordshire, ST5 5BG, United Kingdom. Tel.: 00441782 733925; fax: 00441782 734719. E-mail address: s.stynes@keele.ac.uk (S. Stynes).

Supplemental digital content is available for this article. Direct URL citations appear in the printed text and are provided in the HTML and PDF versions of this article on the journal's Web site (www. painjournalonline.com).

PAIN 159 (2018) 728-738

Copyright $\odot 2018$ The Author(s). Published by Wolters Kluwer Health, Inc. on behalf of The International Association for the Study of Pain. This is an open-access article distributed under the terms of the Creative Commons Attribution-Non Commercial License 4.0 (CCBY-NC), where it is permissible to download, share, remix, transform, and buildup the work provided it is properly cited. The work cannot be used commercially without permission from the journal.

http://dx.doi.org/10.1097/j.pain.00000000000001147 pain, in both primary and secondary care settings. ${ }^{16,19}$ Patients with low back-related leg pain (LBLP) suffer more severe pain and disability, take longer to recover, and lose more time from work ${ }^{14,27,41}$ compared with those with pain in the lower back alone.

When patients present with LBLP, once serious pathology (such as tumours, cauda equina compression, fracture, and inflammatory causes) is ruled out, the differential diagnosis is between leg pain that is due to spinal nerve root involvement (commonly called sciatica) or to nonspecific pain in the leg thought to be referred from structures in the back (eg, disk/ muscle/joint) but not involving the nerve root.

This is a rather broad brush categorisation, however, and currently there is a gap in the evidence regarding whether individual items from the clinical assessment can be used to identify hitherto unrecognised subgroups of patients with LBLP who have distinct presentations of symptoms and characteristics. Early identification and differentiation of subgroups of LBLP may provide more help when informing patients about prognosis, tailoring treatment plans to match profiles, and guiding the need for referrals to specialist services in a timely fashion.

The objective of this study was to use items from clinical assessment to identify new subgroups in an unselected primary care population consulting with LBLP. Statistical modelling, such as latent class analysis, provides a method of classifying patients and may lead to the identification of clusters of patients with similar characteristics over and above the binary diagnostic categories of sciatica or referred leg pain. Clusters identified in this way were compared for baseline demographic, pain, physical function, psychosocial and work features, risk of persistent disability, and findings from magnetic resonance imaging (MRI) of 
the lumbar spine. Key characteristics reflecting pain, disability, psychological status, and perceived recovery were compared at 4 and 12 months and the clinical course, in terms of monthly pain and disability scores over 12 months for the individual clusters, was described and compared with that of the clinically defined groups of patients with LBLP with and without a diagnosis of sciatica.

\section{Methods}

This study used data from primary care consulters with LBLP taking part in the Assessment and Treatment of Leg pain Associated with the Spine (ATLAS) multicentre prospective observational cohort study (see Fig. 1 for ATLAS study flow diagram). Details of the protocol and baseline data results have been published. ${ }^{20,21}$ A brief overview of the ATLAS study methods is given here. Adults aged 18 years and over with LBLP of any duration and severity, who consulted their family doctor (general practitioner), were invited to take part in the ATLAS study. Patients were not eligible if they were receiving treatment, at the time of the study, for their back and leg pain. Leg pain was defined as any pain or unpleasant or abnormal sensation such as pins and needles or numbness, spreading from the back beyond the gluteal fold into the leg. Potentially eligible patients were sent a letter including information about the study, an invitation to attend a research clinic, and baseline questionnaires to complete.

All patients attending the ATLAS research clinic who gave written consent underwent a standardised clinical assessment by 1 of 7 musculoskeletal physiotherapists who documented at the end of the assessment (1) a clinical diagnosis of either sciatica or referred leg pain and (2) confidence (0\%-100\%) in their diagnosis. Patients received treatment according to need, with most patients receiving physiotherapy intervention and a small number being referred to specialist spinal services for an opinion and consideration of further treatment options such as injections and/ or surgery (Ref. 20 for more details). Within 2 weeks of their assessment (providing there were no contraindications to the procedure), patients had a lumbar spine MRI scan as part of the study. A senior consultant musculoskeletal radiologist provided a clinical report indicating presence or absence of nerve root compression blind to any clinical information about the patient other than that the patient had LBLP.

Self-report measures were collected with questionnaires at baseline, 4 months, and 12 months. Monthly measures for leg and back pain intensity and disability were collected over 12 months, using brief postal questionnaires.

\subsection{Variables included in the latent class modelling}

There is no restriction in latent class (LC) modelling on the number of variables or measurement level to model the clusters. ${ }^{44}$ Twelve variables were a priori chosen from the larger set of available selfreport and clinical assessment findings. Variable selection was based on (1) expert consensus from a Delphi study on items from clinical assessment considered most important for distinguishing sciatica from referred leg pain in patients with LBLP ${ }^{22}$ and (2) clinical features of sciatica identified in a systematic review of LBLP classification systems. ${ }^{38}$

Two variables were on a continuous scale (0-10) (leg pain intensity and back pain intensity). The remaining variables were binary (yes/no): subjective sensory changes in the lower limb; below knee pain; leg pain worse than back pain; leg pain on cough,sneeze or strain; leg pain on forward or backward spinal bend; positive neural tension test (straight leg raise or slump or femoral nerve stretch); and myotomal (strength) deficit, reflex deficit, and sensory deficit. Appendix (available as Supplemental Digital Content 1, available online at http://links.Iww.com/PAIN/ A522) for description of variables.

\subsection{Latent class model development}

Latent class modelling aims to identify unobserved heterogeneity in a population and to find meaningful groups that are similar in their responses to measured variables ${ }^{28}$ with minimal withingroup variation and maximum between-group variation. ${ }^{18}$ Latent class models were fitted consecutively starting with a 2 cluster solution. The optimal number of clusters was determined by a combination of the following:

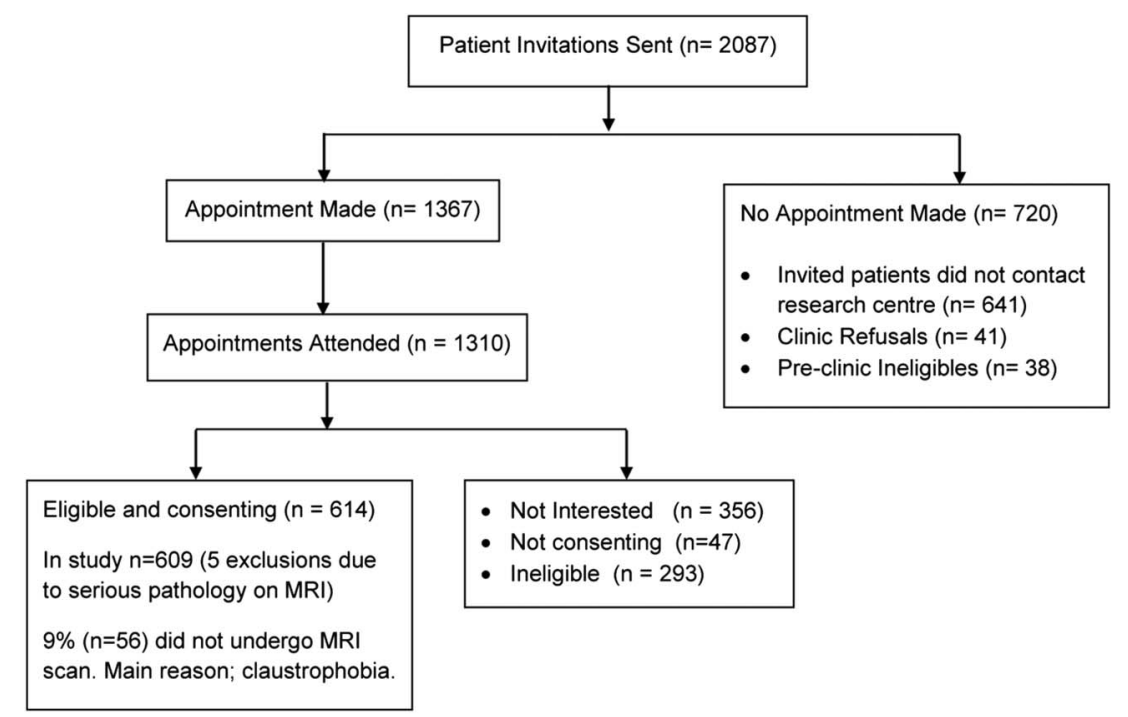

Figure 1. ATLAS study flow diagram (adapted from Konstantinou et al. 2015 Fig. 1 p3 [21]). Konstantinou K, Dunn KM, Ogollah R, Vogel S, Hay EM; ATLAS study research team. Characteristics of patients with low back and leg pain seeking treatment in primary care: baseline results from the ATLAS cohort study. BMC Musculoskelet Disord 2015;16:332-015. ATLAS, Assessment and Treatment of Leg pain Associated with the Spine. 
(1) Goodness of fit statistics: Bayesian information criterion (BIC) (a model with lower BIC is preferred) and the bootstrapped parametric likelihood ratio test which assesses if the addition of a cluster significantly improves the model fit. ${ }^{31}$

(2) Uncertainty of classification measures: entropy measuring the distinction between classes, $(0-1$, where number closer to 1 is optimal), ${ }^{5}$ and average posterior probabilities ${ }^{4}$ where values should exceed 0.7 , indicating clear separation for individuals allocated to that cluster.

(3) At least $5 \%$ of the sample in each cluster. ${ }^{45}$

(4) Face validity of the clusters in terms of their clinical interpretability.

When assigning a "descriptive label" to the clusters, the following was taken into consideration:

(1) Probabilities of a positive response (range 0-1) to the categorical clinical assessment items entered in the LC modelling. A probability of 1 means that all patients in that cluster responded "yes" to that item for example, all had "pain below the knee." Probabilities closer to 0.5 reflect more ambiguity in distinguishing clusters. ${ }^{13}$

(2) Average back and leg pain intensity of patients within the cluster.

(3) Proportion of patients within the cluster with a clinical diagnosis (made by the assessing physiotherapist at the end of assessment) of referred leg pain or sciatica.

\subsection{Cluster characteristics}

Baseline characteristics were compared across the identified clusters. These included age, sex, socioeconomic status, body mass index (height and weight measured in clinic), currently smoking, time off work (only for those at work), pain duration, pain trajectory over the previous year dichotomised as either "mild" or "moderate/severe" based on 7 available responses ranging from first ever episode to severe pain all the time, ${ }^{7}$ presence of widespread pain derived from the shaded body manikin ${ }^{23}$ and defined as pain present above and below the waist, in the right and left-hand sides of the body and in the axial skeleton, ${ }^{43}$ neuropathic (self-report) pain score (Self-report Leeds Assessment of Neuropathic Symptoms and Signs questionnaire ${ }^{2}$ scored from 0 to 24 , with values $\geq 12$ indicating possible neuropathic pain), sciatica bothersomeness index (SBI) (scored from 0 to 24, based on self-reported ratings (0-6) of bothersomeness of (1) leg pain, (2) numbness or tingling in the leg, foot, or groin, (3) weakness in the leg/foot, and (4) back or leg pain while sitting giving a composite score from 0 to 24 higher scores indicating worse symptoms), ${ }^{32}$ pain self-efficacy (scored from 0 to 60 , higher scores representing greater pain self-efficacy beliefs), ${ }^{30}$ anxiety and depression using the Hospital Anxiety and Depression Scale ${ }^{46}$ scored from 0 to 21 with a score of $\geq 11$ indicative of probable depression/anxiety, risk of poor outcome in terms of back pain-related disability using the STarT Back Tool ${ }^{15}$ with cutoff scores to predict low, medium, or high risk, number of comorbidities (from a list of 5 conditions: chest problems, heart problems, hypertension, diabetes, and circulation problems in legs), sleep disturbances (self-report) due to LBLP, and general health (Short Form Health Questionnaire $)^{42}$ ranked as either good/very good/excellent or fair/poor. A single value for health status index was calculated from the EQ-5D-3L ${ }^{10}$ between zero and 1, with values closer to 1 indicating better quality of health. Also compared among clusters was the proportion of patients with MRI evidence of nerve root compression and the proportion of patients where clinicians had high confidence in their diagnosis of either referred leg pain or sciatica (dichotomised to at least $80 \%$ confident in diagnosis (yes or no), at this cutoff the inter-rater reliability is high ${ }^{39}$ ).

\subsection{Clinical course}

The clinical course of the identified clusters was examined over a 12-month period for leg pain, LBP, and back and leg painrelated disability. Leg and back pain intensity were measured using the mean of three 0 to 10 numerical rating scores (NRS) for current pain and least and usual pain over the previous 2 weeks. ${ }^{9}$ Disability was measured using the sciatica version of the Roland Morris Disability Questionnaire (RMDQ) with total score ranging from 0 to 23, higher values representing greater disability. ${ }^{32,35} \mathrm{At}$ 4 and 12 months, self-report characteristics to reflect pain (SBI, pain self-efficacy, and possible neuropathic pain), psychological status (Hospital Anxiety and Depression Scale, 12 month only), and health status (EQ-5D-3L) were compared for the identified clusters.

The proportion of patients referred to secondary care for spinal specialist opinion within the clusters was described, and global perceived recovery from baseline was compared across the clusters with recovery defined as "completely recovered" or "much better."

Latent class modelling was performed in Mplus version 5 (Muthen and Muthen, Los Angeles, CA). Graphs of clinical course were performed in Stata 14 (StataCorp, College Station, TX). All other analyses were performed in SPSS version 21. Each characteristic was compared across the number of identified clusters using analysis of variance for continuous variables (Kruskal-Wallis test when normality and homogeneity of variance assumptions were not met) and Pearson $\chi^{2}$ test (Fisher exact test used for cell frequencies $<5$ ) for categorical variables. Analyses were 2 tailed and considered statistically significant if $P<0.05$.

\section{Results}

At baseline, data were available for 609 LBLP consulters (63\% female, mean [SD] age 50 [13.9] years). Forty-three percent $(n=$ 251) of patients had leg pain for less than 6 weeks, and $36 \%$ ( $n=$ 212) had leg pain for greater than 3 months. Based on clinical assessment, clinicians diagnosed $74 \%(n=452)$ of the patients as having sciatica. On neurological examination, 54\% ( $n=327)$ of patients had either myotomal, reflex, or sensory deficit of the lower limb. Monthly questionnaire response rates for pain and disability scores (Table 1) ranged from $46 \%$ (282/609) to $75 \%$ (450/609). Overall response rates to 4- and 12-month questionnaires were $66 \%$ and $74 \%$, respectively. Response rates for individual clusters were similar to the overall average across the 5 clusters.

\subsection{Model development}

A 5 cluster LC solution was optimal (Table 2 for indices of fit data) because the BIC was lowest and compared with 2, 3, and 4 cluster solution, the entropy was highest (0.74). Entropy improved in the 6 cluster solution (0.79) but the BIC was higher. The bootstrapped likelihood ratio test $P$-value remained significant for all cluster solutions suggesting the model fit improved every time a cluster was added to the model. With 7 clusters, the sample size of the smallest cluster was below $4 \%$. There was a high probability of individuals in the 5 cluster solution being classified in their allocated group, with all average probabilities $>0.80$. 
Table 1

Monthly response rates to questionnaires.

\begin{tabular}{ccc}
\hline Month & No. of participants & $\begin{array}{c}\text { Follow-up response rate compared with } \\
\text { baseline, } \%\end{array}$ \\
\hline 0 & 609 & 100.0 \\
\hline 1 & 455 & 74.7 \\
\hline 2 & 410 & 67.3 \\
\hline 3 & 396 & 65.0 \\
\hline 4 & 402 & 66.0 \\
\hline 5 & 282 & 46.3 \\
\hline 6 & 325 & 53.4 \\
\hline 7 & 300 & 49.3 \\
\hline 8 & 308 & 50.6 \\
\hline 9 & 286 & 47.0 \\
\hline 10 & 287 & 47.1 \\
\hline 11 & 287 & 47.1 \\
\hline 12 & 450 & 73.9 \\
\hline
\end{tabular}

Bolded row represents full questionnaires, the rest are short monthly questionnaires on pain severity and disability (RMDQ).

RMDQ, Roland Morris Disability Questionnaire.

\subsection{Description of clusters}

The 5 clusters' response probabilities to individual clinical assessment items and their corresponding back and leg pain intensity is displayed in Figure 2.

Patients in cluster 1 ( $\mathrm{n}=104,17 \%)$ had moderate LBP (mean 5.3, SD 1.7), low intensity leg pain (mean 3.1, SD 1.4), and moderate probability of subjective sensory changes (0.43). All other clinical items had very low probability of being positive $(\leq 0.22)$. Eighty-one percent were given a "referred pain" diagnosis by the assessing physiotherapists. On the basis of these characteristics, we assigned the label "referred leg pain" to this cluster.

Patients in cluster 2 ( $n=122,20 \%$ ) had low intensity back (mean 3.4, SD 1.4) and leg pain (mean 2.6, SD 1.2), high probability of below knee pain (0.7) and moderate probability of subjective sensory changes (0.57), objective sensory deficits (0.42), and positive neural tension (0.52). Eighty-one percent were given a "sciatica" clinical diagnosis by the assessing physiotherapists. Based on these characteristics, we assigned the label "mild sciatica" to this cluster.

Patients in cluster 3 ( $n=188,31 \%)$ had moderate leg and back pain with slightly higher leg pain (mean 5.5, SD 1.3) than back pain (mean 5.0, SD 1.5) intensity. They had very high probability of below knee pain (0.86) and positive neural tension (0.83) and low probability of reflex or myotome deficit $(<0.3)$ but higher probability of sensory deficit (0.56). Ninety-three percent were given a "sciatica" clinical diagnosis by the assessing physiotherapist. Based on these characteristics, we assigned the label "moderate sciatica" to this cluster.

Patients in cluster 4 ( $n=69,11 \%)$ had high intensity back pain (mean 8.0, SD 1.3) and leg pain (mean 8.5, SD 1.1) and high probability of most clinical assessment items being positive, especially leg pain worse than back pain (0.86), below knee pain (0.95), and neural tension (0.9). They had the highest probability among all the clusters of neurological deficits $(0.38,0.32$, and 0.48 for reflex, myotome, and sensory deficit, respectively) and positive cough/sneeze (0.63). One hundred percent were given a "sciatica" clinical diagnosis by the assessing physiotherapists. Based on these characteristics, we assigned the label "severe sciatica" to this cluster.

Patients in cluster 5 ( $n=126,21 \%)$ had high intensity back pain (mean 7.5, SD 1.4) and leg pain (mean 7.2, SD 1.4) and high probability $(0.7)$ of pain below the knee. They were not likely to have positive neural tension (0.34) or leg pain worse than back pain (0.31) and likely to have subjective sensory changes (0.63) and objective sensory deficit (0.46) compared with other clusters. They had a very similar response to clinical assessment as cluster 2 but with much higher pain severity. Seventy-one percent were given a "sciatica" clinical diagnosis by the physiotherapist. Based on these characteristics, we assigned the label "atypical sciatica" to this cluster.

\subsection{Cluster characteristics}

The clusters did not differ significantly in age, sex, or body mass index (Table 3). There was a greater proportion of smokers in clusters 4 (severe sciatica) and 5 (atypical sciatica), and these 2 clusters had more patients categorised as manual workers.

In ascending order of severity for pain (back and leg pain intensity and Self-report Leeds Assessment of Neuropathic Symptoms and Signs neuropathic pain score), SBI, and disability (RMDQ) scores, was cluster 2 (mild sciatica), cluster 1 (referred leg pain), cluster 3 (moderate sciatica), cluster 5 (atypical sciatica), and cluster 4 (severe sciatica). In cluster 5, 24\% of patients had leg pain for more than 1 year compared with $13 \%$ or less for the other 4 clusters. The proportions of patients with moderate/ severe pain over the last year was lowest in cluster 1 (30\%) and highest in cluster 5 (71\%).

The STarT Back tool grouped $69 \%$ and $64 \%$ of patients in clusters 4 and 5 , respectively, as being at high risk of poor

\section{Table 2}

Statistical indices of fit of the latent cluster models of patients with LBLP ( $n=609)$.

\begin{tabular}{clccc}
\hline No. of clusters & BIC & Bootstrapped parametric LRT, $\boldsymbol{P}$ & Entropy & Smallest sample size (\%) \\
\hline 2 & $12,101.838$ & $<0.001$ & 0.714 & $281(46.3)$ \\
\hline 3 & $12,005.723$ & $<0.001$ & 0.738 & $147(24.1)$ \\
\hline 4 & $11,951.353$ & $<0.001$ & 0.728 & $121(19.9)$ \\
\hline 5 & $11,941.422$ & $<0.001$ & 0.742 & $69(11.3)$ \\
\hline 6 & $11,974.379$ & $<0.001$ & 0.791 & $51(8.4)$ \\
\hline 7 & $12,002.221$ & $<0.001$ & 0.802 & $24(3.9)$ \\
\hline
\end{tabular}

* The number (proportion) of patients in the smallest class; at least $5 \%$ of sample should be in each class. The bold text indicates the model selected as having the optimal number of clusters.

BIC, Bayesian information criteria; LBLP, low back-related leg pain; LRT, likelihood ratio test. 


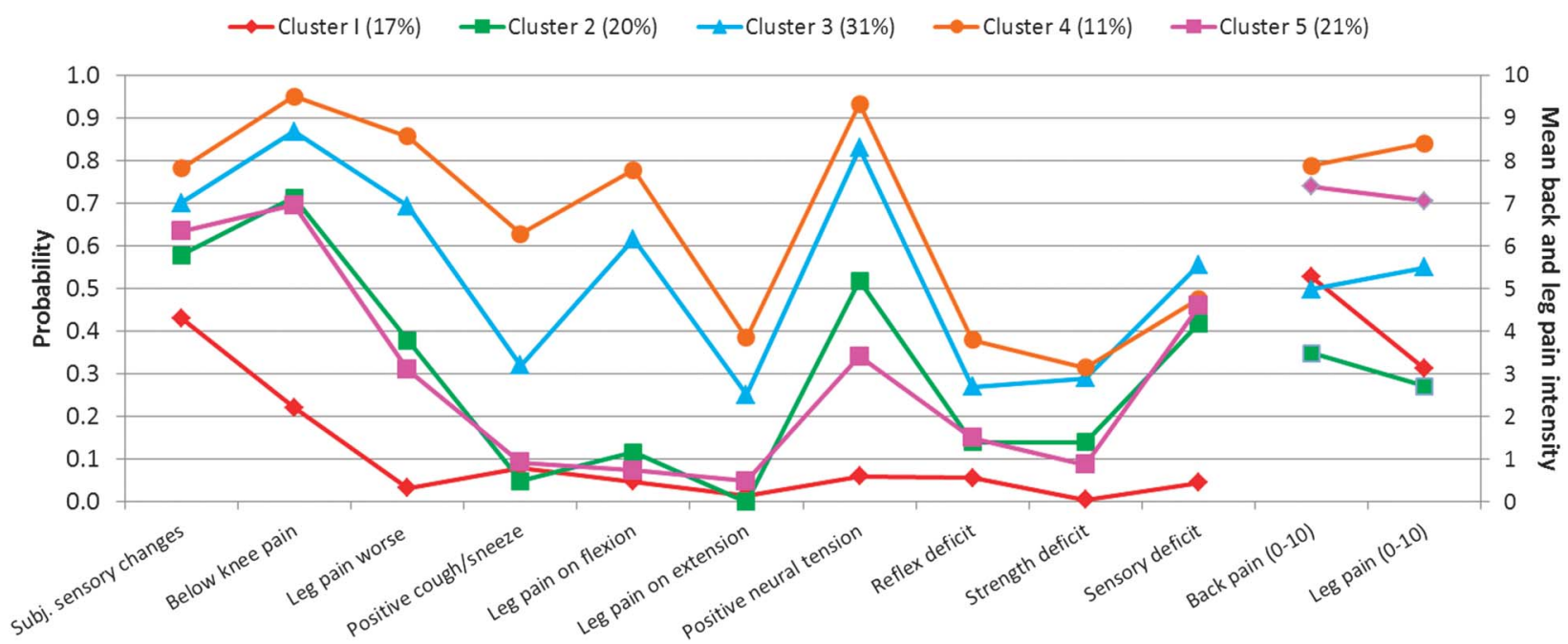

Figure 2. Five cluster latent class analysis solution. Item response probabilities of categorical variables (left vertical axis) and baseline mean leg and back pain intensity (right vertical axis).

prognosis in terms of disability. Clusters 1 and 3 had approximately one-third of patients categorised as high risk, and only $13 \%$ of patients in cluster 2 were at high risk. Anxiety and depression cases were highest for cluster 4 , followed by cluster 5 . Cluster 2 had the lowest proportion of patients categorised as anxious or depressed. Cluster 1 (referred leg pain) had higher anxiety levels than clusters 2 and 3. Pain self-efficacy was lowest for cluster 4 and highest for cluster 2. A higher proportion in cluster 5 reported poorer general health, more widespread pain, and 2 or more other health problems. EQ-5D summary index was considerably lower for cluster 4 (mean 0.13, SD 0.3) and cluster 5 (mean 0.29, SD 0.3), indicating poorer quality of health.

Clinicians had high confidence $(\geq 80 \%)$ in their diagnosis for $90 \%$ of patients in cluster 4 , whereas in cluster 5 , just over half (51\%) of the group were diagnosed by clinicians with high confidence. Concordant MRI findings of nerve root compression were highest in cluster 4 (89\%) and lowest in cluster 1 (26\%). Clusters 2 and 5 had similar proportion of patients with nerve root compression on $\mathrm{MRI}$ ( $51 \%$ and $46 \%$, respectively). Cluster characteristics are summarised in Table 3.

\subsection{Clinical course}

Disability, leg pain, and LBP scores improved over time for all clusters. Similar to the baseline pattern, the order of severity of monthly leg pain (Fig. 3) and disability scores (Fig. 4) remained almost the same across the 5 clusters with clusters 4 and 5 remaining with the highest pain and disability scores at 12 months.

The most reduction in pain and disability for all clusters was seen in the first 4 months, after which the values remained relatively stable. Cluster 2 (mild sciatica) presented with the mildest pain at baseline and remained relatively unchanged over the year.

When patients are classified to 2 groups according to the clinical diagnosis of either referred leg pain $(n=157)$ or sciatica ( $n$ $=452$ ), their clinical course was very similar for leg pain (Fig. 3), disability (Fig. 4), and back pain (Fig. 5).

Among the whole cohort, 70 patients were referred to specialist spinal services. Patients in the moderate, severe, and atypical sciatica clusters accounted for most of these onward referrals. On all key characteristics (Table 4), scores improved across all domains measured at 4 and 12 months. Cluster 5 showed least improvement and had the lowest proportion of patients reporting recovery (completely recovered or much better) at 4 months (19\%) and 12 months (27\%). At 12 months, overall recovery proportions in the other 4 clusters ranged from $37 \%$ in cluster $1 \%$ to $45 \%$ in cluster 2 .

\section{Discussion}

This study is the first to use LC modelling to identify potentially clinically relevant clusters of primary care consulters with symptoms of low back and leg pain. Clusters were identified based on response to clinical assessment items used to guide diagnosis in patients with LBLP. One cluster represents a referred leg pain group. Three clusters represent varying severity of sciatica (mild, moderate, and severe). The fifth cluster (atypical sciatica) is more difficult to define, with similar responses to clinical assessment items as the mild sciatica cluster but with much higher pain intensity. The work gives a novel insight into the clinical spectrum of LBLP, not previously highlighted in the literature.

The main items that distinguished between the 4 "sciatica" clusters were severity of back and leg pain, whether leg pain was worse than back pain, location of the leg pain (below the knee), and presence of neural tension. Neurological examination tests did not add much information to distinguishing the sciatica clusters, neither did leg pain on lumbar extension. The probability of having leg pain on forward bending was higher for patients in clusters 3 and 4 which could be explained by similarity to mechanics of performing a straight leg raise.

Two clusters ("severe sciatica" and "atypical sciatica") had considerably greater severity in terms of pain, disability, risk of poor outcome, work impact, and psychological and healthrelated characteristics. Mean disability levels for the "severe sciatica" cluster 4, measured by RMDQ, was 16.7 comparable with secondary care sciatica populations in clinical trials involving surgery (16.4). ${ }^{33}$ By comparison, the "mild sciatica" cluster had the lowest level of disability (8.6) comparable with other primary care LBP cohorts with and without leg pain $\left(8.8,{ }^{16}[8.7]^{24}\right)$. In cluster 5, "atypical sciatica," although $70 \%$ of patients had a clinical diagnosis of sciatica, clinicians had low confidence in 
Table 3

Baseline characteristics of the 5 clusters of patients with low back-related leg pain.

\begin{tabular}{|c|c|c|c|c|c|c|}
\hline Sociodemographics & Cluster 1 & Cluster 2 & Cluster 3 & Cluster 4 & Cluster 5 & $P^{*}$ \\
\hline Denominatort & $\begin{array}{l}\text { Referred leg pain } \\
(n=104)\end{array}$ & $\begin{array}{l}\text { Mild sciatica } \\
(n=122)\end{array}$ & $\begin{array}{l}\text { Moderate sciatica } \\
(\mathrm{n}=188)\end{array}$ & $\begin{array}{l}\text { Severe sciatica } \\
(n=69)\end{array}$ & $\begin{array}{l}\text { Atypical sciatica } \\
(n=126)\end{array}$ & \\
\hline $\begin{array}{l}\text { Age }(\mathrm{y}) \text { mean }(\mathrm{SD}) \\
\text { Age category } 65+\end{array}$ & $\begin{array}{r}47.2(13.8) \\
13(12.5)\end{array}$ & $\begin{array}{r}50.4(13.3) \\
17(13.9)\end{array}$ & $\begin{array}{r}50.9(14.4) \\
33(17.6)\end{array}$ & $\begin{array}{r}49.2(12.7) \\
7(10.1)\end{array}$ & $\begin{array}{r}51.9(14.1) \\
22(17.5)\end{array}$ & $\begin{array}{l}0.111 \\
0.238\end{array}$ \\
\hline Sex, female & $76(73.1)$ & $72(59.0)$ & $113(60.1)$ & $42(60.9)$ & $80(63.5)$ & 0.187 \\
\hline Current smoker & $27(26.0)$ & $29(23.8)$ & $52(27.7)$ & $30(43.5)$ & $56(44.4)$ & $<0.001$ \\
\hline BMI (607) category: obese/morbidly obese & $31(29.8)$ & $49(40.5)$ & $78(41.5)$ & $36(52.2)$ & $54(43.2)$ & 0.056 \\
\hline Socioeconomic status: manual occupation (593) & $41(39.4)$ & $43(36.1)$ & $85(46.4)$ & $36(55.4)$ & $78(63.9)$ & $<0.001$ \\
\hline $\begin{array}{l}\text { Self-certified time off work (363) } \\
\text { Or current sick note (365) }\end{array}$ & $\begin{array}{l}25(35.7) \\
22(31.4)\end{array}$ & $\begin{array}{l}20(25.6) \\
16(20.3)\end{array}$ & $\begin{array}{l}42(35.0) \\
34(28.3)\end{array}$ & $\begin{array}{l}11(29.7) \\
14(37.8)\end{array}$ & $\begin{array}{r}8(13.8) \\
14(16.2)\end{array}$ & $\begin{array}{l}0.032 \\
0.279\end{array}$ \\
\hline Back pain duration $(607)>6$ wk & $64(61.5)$ & $72(59.0)$ & $117(62.6)$ & $47(68.1)$ & $89(71.2)$ & 0.279 \\
\hline $\begin{array}{l}\text { Leg pain duration }(583)>6 \text { wk } \\
\quad>3 \mathrm{mo} \\
\quad>12 \mathrm{mo}\end{array}$ & $\begin{array}{l}50(50.5) \\
31(31.3) \\
15(15.2)\end{array}$ & $\begin{array}{l}52(45.2) \\
24(20.9) \\
10(8.7)\end{array}$ & $\begin{array}{r}105(57.7) \\
69(37.9) \\
24(13.2)\end{array}$ & $\begin{array}{c}38(57.6) \\
20(30.3) \\
3(4.5)\end{array}$ & $\begin{array}{l}87(71.9) \\
68(56.2) \\
29(24.0)\end{array}$ & $\begin{aligned} & 0.001 \\
< & 0.001 \\
< & 0.001\end{aligned}$ \\
\hline Back pain intensity, mean (SD) & $5.3(1.7)$ & $3.4(1.4)$ & $5.0(1.5)$ & $8.0(1.3)$ & $7.5(1.4)$ & $<0.001$ \\
\hline Leg pain intensity, mean (SD) & $3.1(1.4)$ & $2.6(1.2)$ & $5.5(1.3)$ & $8.5(1.1)$ & $7.2(1.4)$ & $<0.001$ \\
\hline RMDQ disability score (0-23) mean (SD) (607) & $11.5(5.6)$ & $8.6(5.0)$ & $12.8(4.7)$ & $16.7(5.1)$ & $15.1(5.5)$ & $<0.001$ \\
\hline $\begin{array}{l}\text { Sciatica bothersomeness index (0-24) mean } \\
\text { (SD) (582) }\end{array}$ & $11.1(4.9)$ & $10.0(4.4)$ & $14.7(4.0)$ & $19.8(3.5)$ & $17.2(4.4)$ & $<0.001$ \\
\hline $\begin{array}{l}\text { S-LANSS, possible neuropathic pain }(\geq 12) \\
(606)\end{array}$ & $37(35.6)$ & $44(36.4)$ & $100(53.2)$ & $45(66.2)$ & $67(53.6)$ & $<0.001$ \\
\hline $\begin{array}{l}\text { STarT back subgroup (589) } \\
\text { Low risk } \\
\text { Medium risk } \\
\text { High risk }\end{array}$ & $\begin{array}{l}17(17.0) \\
52(52.0) \\
31(31.0)\end{array}$ & $\begin{array}{l}44(37.0) \\
59(49.6) \\
16(13.4)\end{array}$ & $\begin{array}{r}16(8.8) \\
105(58.0) \\
60(33.1) \\
\end{array}$ & $\begin{array}{c}0(0.0) \\
20(30.8) \\
45(69.2)\end{array}$ & $\begin{array}{c}5(4.0) \\
40(32.3) \\
79(63.7) \\
\end{array}$ & $<0.001$ \\
\hline Widespread pain (592)‡ & $50(49.9)$ & $48(40.7)$ & $72(38.9)$ & $15(22.4)$ & $65(54.2)$ & $<0.001$ \\
\hline $\begin{array}{l}\text { HADS anxiety (607) subscale } \\
\text { Probable§ }\end{array}$ & $32(31.1)$ & $20(16.4)$ & $34(18.2)$ & $33(47.8)$ & $52(41.3)$ & $<0.001$ \\
\hline $\begin{array}{l}\text { HADS depression subscale } \\
\text { Probable§ }\end{array}$ & $12(11.5)$ & $9(7.4)$ & $21(11.2)$ & $26(37.7)$ & $30(23.8)$ & $<0.001$ \\
\hline Pain self-efficacy score (0-60), mean (SD) (593) & $37.6(12.4)$ & $42.9(12.5)$ & $34.7(12.3)$ & $22.5(15.6)$ & $28.4(14.3)$ & $<0.001$ \\
\hline EQ-5D-3L summary index (590) & $0.54(0.3)$ & $0.66(0.2)$ & $0.48(0.3)$ & $0.13(0.3)$ & $0.29(0.3)$ & $<0.001$ \\
\hline
\end{tabular}

\begin{tabular}{|c|c|c|c|c|c|c|}
\hline \multicolumn{7}{|l|}{ Comorbidities } \\
\hline Two or more other health problems & $16(15.4)$ & $15(12.3)$ & $21(11.2)$ & $5(7.2)$ & $23(18.3)$ & 0.139 \\
\hline \multicolumn{7}{|l|}{ General health (608) } \\
\hline Fair/poor & $38(36.5)$ & $31(25.5)$ & $59(31.4)$ & $32(47.1)$ & $62(49.2)$ & $<0.001$ \\
\hline Sleep disturbance (yes) \| & $69(66.3)$ & $73(59.8)$ & $133(70.7)$ & $61(88.4)$ & $92(73.0)$ & 0.001 \\
\hline Clinical diagnosis sciatica & $20(19.2)$ & $99(81.1)$ & $175(93.1)$ & $69(100.0)$ & $89(70.6)$ & $<0.001$ \\
\hline Clinician confidence in diagnosis $\geq 80 \%$ & $72(69.2)$ & $75(61.4)$ & $156(83.0)$ & 63 (91.3) & $70(55.6)$ & $<0.001$ \\
\hline \multicolumn{7}{|l|}{ MRI (554) } \\
\hline Clear or possible nerve root compression & 25 (26.3) & $56(50.5)$ & $106(63.1)$ & $57(89.1)$ & $53(45.7)$ & $<0.001$ \\
\hline Disk prolapse & $17(68.0)$ & 47 (83.9) & $84(79.2)$ & $49(86.0)$ & $33(62.3)$ & \\
\hline Stenosis & $6(24.0)$ & 7 (12.5) & $19(17.9)$ & 7 (12.3) & $16(30.2)$ & \\
\hline Other 9 & $2(8.0)$ & $2(3.6)$ & $3(2.8)$ & $1(1.8)$ & $4(7.5)$ & \\
\hline
\end{tabular}

* Significance $P$-value $(\alpha=0.05)$ for the difference between patients in the 5 latent clusters on ANOVA for continuous variables (Kruskil-Wallis for variables BMI, HADS (depression), and EQ-5D) and $\chi^{2}$ test for categorical variables (Fisher exact test for variable socioeconomic cluster and general health).

† Denominator varies for some participants due to missing data or nonapplicable cases. All figures are frequencies (percentages) unless otherwise stated as mean (SD).

‡ Widespread pain derived from the shaded body manikin (defined as pain present above and below the waist in the right and left-hand sides of the body and in the axial skeleton).

$\S$ Score of $\geq 11$ indicative of probable depression/anxiety.

$\|$ Question on back and/or leg pain associated sleep disturbance was asked during the clinical assessment.

I Other MRI diagnoses $(n=11)$ included spondylolisthesis, epidural lipomatosis, synovial cyst, and osteophyte.

ANOVA, analysis of variance; BMI, body mass index; EQ-5D-3L, EuroQoL; HADS, Hospital Anxiety and Depression Scale; MRI, magnetic resonance imaging; RMDQ, Roland Morris Disability Questionnaire; S-LANSS, Self-report Leeds Assessment of Neuropathic Symptoms and Signs. All figures are frequencies (percentages) unless otherwise stated as mean (SD). 


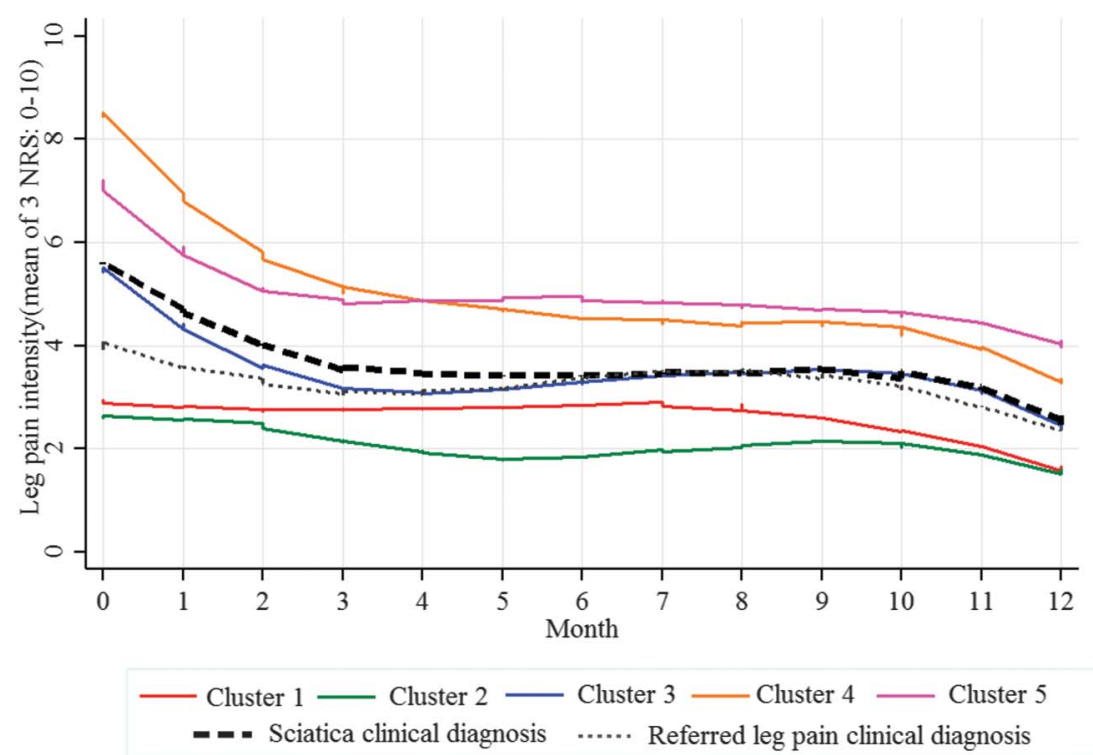

Figure 3. Clinical course over 12 months of monthly leg pain intensity scores (0-10) for the 5 clusters and the clinically diagnosed groups (referred leg pain and sciatica), calculated from the mean of 3 numeric rating scores (NRS) for current and least and usual leg pain over the previous 2 weeks.

their diagnosis (<80\% confidence) in almost half of the patients, and MRI findings confirmed nerve root compression in $46 \%$ of patients. Arguably, labelling this cluster as "sciatica" may be unrepresentative of the signs and symptoms of the condition, and during discussions with clinicians, this was the most difficult group to "label." Only $27 \%$ of patients in cluster 5 reported recovery at 12 months, considerably lower than the other 4 clusters. This perhaps reflects their more complex presentation with more patients in this cluster having longer pain duration, more comorbidities, and a higher proportion with widespread pain.

The observed differences in cluster characteristics at baseline persisted over time. All clusters showed improved pain and disability scores over 12 months, with most improvement seen within the first 3 to 4 months following baseline assessment. Low back pain trajectory studies confirm this early improvement for most patients and show findings similar to our cohort that most patients with LBP remain in some level of pain at 12 months. ${ }^{1,6}$ When patients were classified according to clinical diagnosis of either referred leg pain or sciatica, their clinical course over 12 months was very similar for leg pain, disability, and back pain. The LC modelling gave richer information about the whole LBLP cohort as opposed to considering the group as with or without a clinical diagnosis of sciatica. Cluster 1 (labelled "referred leg pain") and the group of patients with the clinical diagnosis of referred leg pain consist of mostly the same patients; hence, their

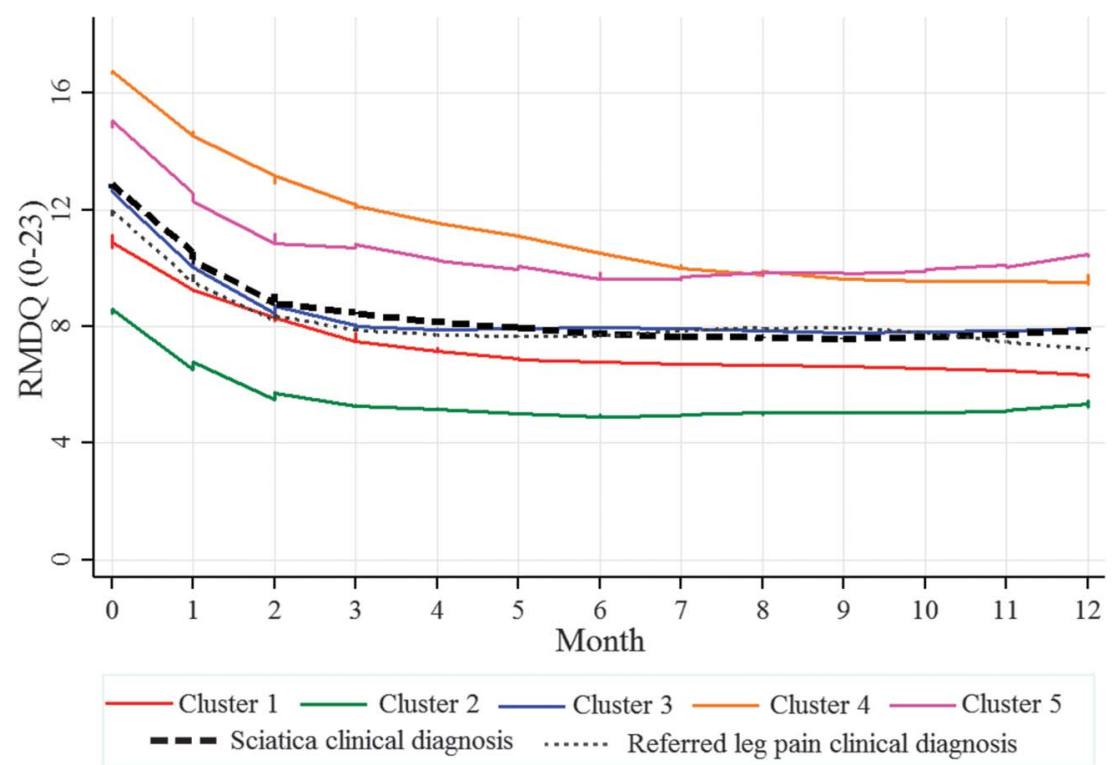

Figure 4. Clinical course over 12 months of disability for the 5 clusters and the clinically diagnosed groups (referred leg pain and sciatica), measured by the monthly mean Roland Morris Disability Questionnaire (RMDQ) score. 


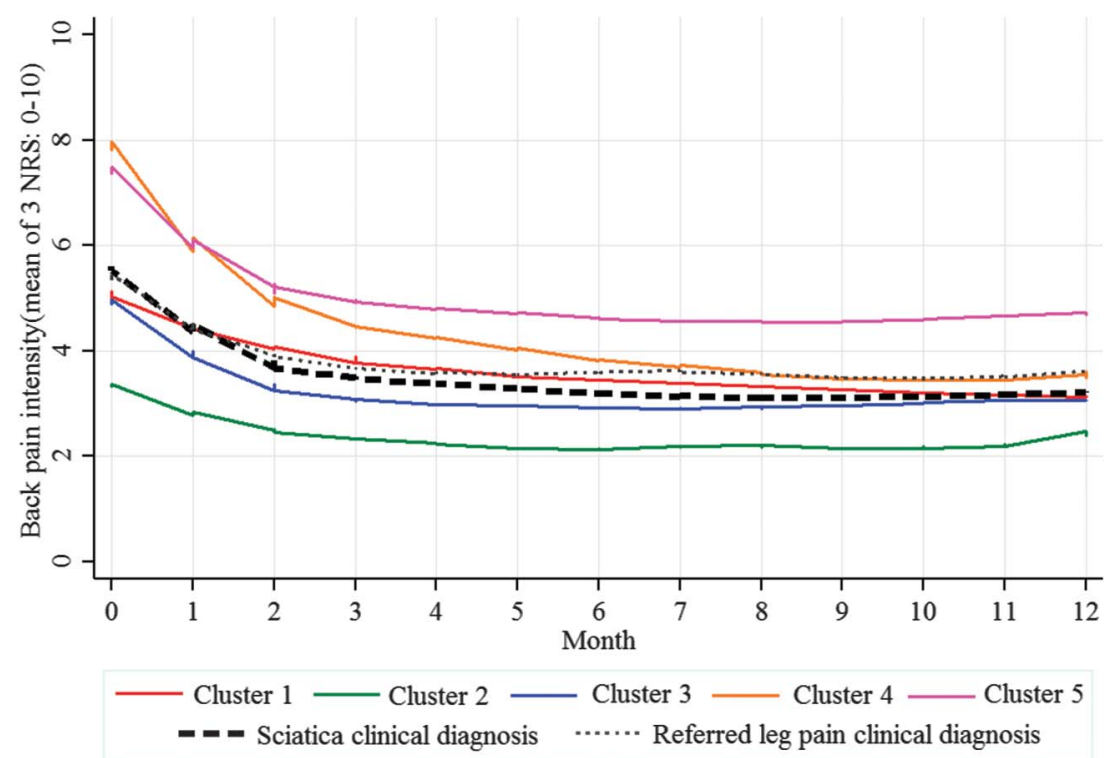

Figure 5. Clinical course over 12 months of monthly back pain intensity scores (0-10) for the 5 clusters and the clinically diagnosed groups (referred leg pain and sciatica), calculated from the mean of 3 numeric rating scores (NRS) for current and least and usual back pain over the previous 2 weeks.

clinical course is similar. Cluster 3 (moderate sciatica) mirrored the clinical course of patients with a clinical diagnosis of sciatica. Clusters 2, 4, and 5, however, revealed the existing variability in terms of characteristics and clinical course in patients with sciatica and provide more detailed information and insight compared with the information provided by the overall average for this group.

Probably, the most extensively investigated LBP and leg pain classification system is the Quebec Task Force Classification system, ${ }^{37}$ which categorises patients with back and leg pain based on pain location and presence of neurological deficit. Patients with leg pain and signs of nerve root involvement were most severely affected in terms of pain, disability, and work ability, ${ }^{17}$ improve more than other LBLP categories over time, but have poorer outcomes measured by absolute disability scores. ${ }^{19}$ This is similar to the clinical course of our "severe sciatica" cluster.

Previous work using longitudinal latent class analysis and pain trajectories identified 4 LBP clusters (with and without leg pain): persistent mild, recovering, fluctuating, and severe chronic. ${ }^{8}$ The severe chronic pain cluster, with the greatest numbers with leg pain (89\%), scored worse on disability scores, psychological distress, and work absence, suggesting it might reflect patients from both our "severe sciatica" and "atypical sciatica" cluster. In acute LBP, similar trajectories were identified, but "pain below the knee" was not associated with membership of any of the clusters. ${ }^{6}$

\subsection{Strengths and limitations}

The key strengths of our study include using a statistical approach to develop clusters based on patient data, with clinical judgement to aid cluster interpretation. The sample represents a true primary care population presenting initially to their general practitioner, with variable symptom severity and duration. The modelling and description of the clusters was based on a comprehensive data set of clinical assessment, self-report and imaging items, and longitudinal data.

A limitation of our study is that although the 5 cluster solution was based on optimal statistical fit of the data and clinical interpretability of the clusters, they may not reflect the precise clustering of patients with LBLP among primary care consulters. Replication of these clusters in other LBLP populations is needed to explore their external validity. Available longitudinal data gave insight to the clinical course of patients within the 5 clusters, but there were missing data at each time point owing to nonresponse to monthly questionnaires or to individual items within the questionnaire. Age and sex characteristics for nonparticipants (invited patients who did not attend the research clinics or were not interested in participation) were similar to those who participated. As we do not have data on other variables, participation bias is possible if participants differed from nonparticipants on certain characteristics.

When considering the clinical course of the 5 clusters, generalizability to primary care may be influenced by nature of patients' involvement in the study. Receiving a lumbar spine MRI scan with subsequent feedback from clinicians in relation to findings and having timely access to appropriate management may have positively influenced patient outcomes. Despite this process, the proportion of patients reporting recovery (completely recovered or much better) was no higher than $45 \%$ for all clusters, and cluster 5 ("atypical sciatica") was considerably lower at 12 months with only $27 \%$ of patients reporting recovery.

\subsection{Clinical implications}

This work gives detailed insight into the complexity of LBLP and shows that information on initial presentation can help classify patients into distinct clusters.

Even within a specific condition such as sciatica, variation is overlooked if only "average" population measures are considered. Heterogeneous study populations in clinical research can potentially confound outcomes, ${ }^{40}$ and recent clinical practice guidelines for LBP treatments conclude that there is insufficient evidence to better match treatment for presentations of leg pain/sciatica. ${ }^{34}$ The clusters identified in this work may represent groups likely to need a different management approach.

Currently management of sciatica is a stepped care approach in those not deteriorating or with signs suggestive of sinister 
Table 4

\section{Key characteristics for 5 clusters at 4 and 12 months.}

\begin{tabular}{|c|c|c|c|c|c|}
\hline & $\begin{array}{l}\text { Cluster } 1 \\
\text { Referred leg pain } \\
(n=104)\end{array}$ & $\begin{array}{l}\text { Cluster } 2 \\
\text { Mild sciatica } \\
(\mathrm{n}=122)\end{array}$ & $\begin{array}{l}\text { Cluster } 3 \\
\text { Moderate sciatica } \\
(\mathrm{n}=188)\end{array}$ & $\begin{array}{l}\text { Cluster } 4 \\
\text { Severe sciatica } \\
(n=69)\end{array}$ & $\begin{array}{l}\text { Cluster } 5 \\
\text { Atypical sciatica } \\
(\mathrm{n}=126)\end{array}$ \\
\hline $\begin{array}{l}\text { HADS anxiety probable, } n(\%) \\
\text { Baseline }(n=609) \\
12 \mathrm{mo}(\mathrm{n}=365)\end{array}$ & $\begin{array}{r}32(31.1) \\
9(15.0)\end{array}$ & $\begin{array}{r}20(16.4) \\
8(10.3)\end{array}$ & $\begin{array}{l}34(18.2) \\
14(11.7)\end{array}$ & $\begin{array}{r}33(47.8) \\
7(20.0)\end{array}$ & $\begin{array}{l}52(41.3) \\
17(23.6)\end{array}$ \\
\hline $\begin{array}{l}\text { HADS depression probable, } n(\%) \\
\text { Baseline }(n=609) \\
12 \text { mo }(n=373)\end{array}$ & $\begin{array}{c}12(11.5) \\
3(4.8)\end{array}$ & $\begin{array}{l}9(7.4) \\
2(2.5)\end{array}$ & $\begin{array}{c}21(11.2) \\
6(5.0)\end{array}$ & $\begin{array}{r}26(37.7) \\
5(13.5)\end{array}$ & $\begin{array}{l}30(23.8) \\
14(19.2)\end{array}$ \\
\hline $\begin{array}{l}\text { EQ-5D-3L summary index }(0-1) \text {, mean (SD) } \\
\text { Baseline }(n=590) \\
\quad 4 \text { mo }(n=341) \\
12 \mathrm{mo}(n=357)\end{array}$ & $\begin{array}{l}0.54(0.30) \\
0.73(0.24) \\
0.72(0.23)\end{array}$ & $\begin{array}{l}0.66(0.20) \\
0.76(0.21) \\
0.77(0.21)\end{array}$ & $\begin{array}{l}0.48(0.30) \\
0.65(0.29) \\
0.68(0.28)\end{array}$ & $\begin{array}{l}0.13(0.30) \\
0.49(0.40) \\
0.62(0.32)\end{array}$ & $\begin{array}{l}0.29(0.30) \\
0.44(0.37) \\
0.53(0.38)\end{array}$ \\
\hline $\begin{array}{l}\text { Sciatica bothersomeness index (SBI) }(0-24) \text {, } \\
\text { mean }(S D) \\
\text { Baseline }(n=582) \\
4 \mathrm{mo}(n=236)^{\star} \\
12 \mathrm{mo}(n=187)^{\star}\end{array}$ & $\begin{array}{r}11.1(4.9) \\
8.5(5.2) \\
9.6(5.4)\end{array}$ & $\begin{array}{r}10.0(4.4) \\
8.5(4.9) \\
8.2(4.7)\end{array}$ & $\begin{array}{l}14.7(4.0) \\
10.2(5.4) \\
10.9(5.7)\end{array}$ & $\begin{array}{l}19.8(3.5) \\
14.5(7.0) \\
13.3(5.6)\end{array}$ & $\begin{array}{l}17.2(4.4) \\
14.3(5.7) \\
14.1(6.1)\end{array}$ \\
\hline $\begin{array}{l}\text { Pain self-efficacy (PSEQ) 0-60, mean (SD) } \\
\text { Baseline }(n=593) \\
4 \mathrm{mo}(n=378) \\
12 \mathrm{mo}(\mathrm{n}=364)\end{array}$ & $\begin{array}{l}37.6(12.4) \\
48.4(10.7) \\
48.6(10.1) \\
\end{array}$ & $\begin{array}{l}42.9(12.5) \\
49.1(12.7) \\
50.0(11.6) \\
\end{array}$ & $\begin{array}{l}34.7(12.3) \\
42.9(14.3) \\
44.1(14.1) \\
\end{array}$ & $\begin{array}{l}22.5(15.6) \\
37.8(18.4) \\
41.7(17.7) \\
\end{array}$ & $\begin{array}{l}28.4(14.3) \\
35.8(17.5) \\
38.4(17.1) \\
\end{array}$ \\
\hline $\begin{array}{l}\text { S-LANSS neuropathic pain score }(\geq 12), n(\%) \\
\text { Baseline }(n=606) \\
\quad 4 \mathrm{mo}(\mathrm{n}=376) \\
12 \mathrm{mo}(\mathrm{n}=348)\end{array}$ & $\begin{array}{r}37(35.6) \\
9(15.3) \\
8(13.8)\end{array}$ & $\begin{array}{l}44(36.4) \\
12(15.6) \\
10(13.7)\end{array}$ & $\begin{array}{r}100(53.2) \\
32(25.4) \\
31(27.0)\end{array}$ & $\begin{array}{l}45(66.2) \\
15(41.7) \\
10(28.6)\end{array}$ & $\begin{array}{l}67(53.6) \\
26(33.3) \\
20(29.9)\end{array}$ \\
\hline $\begin{array}{l}\text { Global perceived recovery (completely } \\
\text { recovered, much better), } n(\%) \dagger \\
4 \mathrm{mo}(\mathrm{n}=394) \\
12 \mathrm{mo}(\mathrm{n}=444)\end{array}$ & $\begin{array}{l}19(31) \\
28(38)\end{array}$ & $\begin{array}{l}37(46) \\
42(45)\end{array}$ & $\begin{array}{l}55(42) \\
88(40)\end{array}$ & $\begin{array}{l}12(32) \\
19(41)\end{array}$ & $\begin{array}{l}16(19) \\
22(27)\end{array}$ \\
\hline
\end{tabular}

* SBI questionnaire only answered by patients whose pain from the back had spread down their legs in the last 2 weeks.

† Compared to 4 (12) months ago, how do you think your back and/or leg pain has changed?

EQ-5D-3L, EuroQoL; HADS, Hospital Anxiety and Depression Scale; mo, months; S-LANSS, Self-report Leeds Assessment of Neuropathic Symptoms and Signs.

pathology, starting with noninvasive treatments and progressing to more invasive treatment options. ${ }^{26}$ Timing and when to move to the next step is not clear, particularly in those with higher pain levels, ${ }^{25}$ and it still remains unknown which patient will benefit from what intervention at which point (eg, conservative management/surgery/injection). ${ }^{29}$ Two of the clusters represent patients that could preferentially respond to this stepped approach (cluster 2 and 3). Cluster 4 patients may benefit from a more intensive initial approach earlier in their management for example, specialist opinion regarding more invasive options (surgery and/or injections). Patients in cluster 1 and cluster 5 may be more suitable for pain management options that include psychosocial interventions.

Levels of depression and anxiety were highest in the clusters with most severe symptoms, which is unsurprising and levels remained highest in cluster 5 at 12 months. Mechanisms driving the high pain and anxiety are potentially different between the 2 groups and management should reflect this. The atypical sciatica cluster resembles profiles of patients with persistent and/or widespread pain, whereas cluster 4 has a clear diagnosis and in the clinical setting is more likely to be considered for treatment options such as injections and/or surgery.

These clusters could be more homogenous groups that represent uniquely different responders to specific interventions. The next step is to consider optimum management pathways for these clusters and formally test whether different management options improve outcomes.

\section{Conclusion}

This work shows the variation in profile and clinical course of patients that present with a seemingly similar condition of LBLP. This is more informative than describing simple averages among a more heterogenous population. We recommend these clusters and their potentially differential treatment responses should be considered in current clinical settings and when designing future studies in the treatment of LBLP including sciatica.

\section{Conflict of interest statement}

The authors have no conflict of interest to declare.

Supported by the National Institute for Health Research (NIHR) funding awards to Siobhan Stynes NIHR/CNO Clinical Doctoral Research Fellowship (CDRF-2010-055) and Kika Konstantinou HEFCE/NIHR Senior Clinical Lectureship. Elaine Hay is an NIHR Senior Investigator. The authors are solely responsible for content of the manuscript. The funders did not participate in study design, data collection, data analysis, interpretation of the data, or preparation for the manuscript. 
Ethical approval for the ATLAS study was granted by the South Birmingham Research Ethics committee, reference number 10/ H1207/82.

\section{Appendix A. Supplemental digital content}

Supplemental digital content associated with this article can be found online at http://links.Iww.com/PAIN/A522.

\author{
Article history: \\ Received 28 July 2017 \\ Received in revised form 27 October 2017 \\ Accepted 22 December 2017 \\ Available online 9 January 2018
}

\section{References}

[1] Axen I, Leboeuf-Yde C. Trajectories of low back pain. Best Pract Res Clin Rheumatol 2013;27:601-12.

[2] Bennett MI, Smith BH, Torrance N, Potter J. The S-LANSS score for identifying pain of predominantly neuropathic origin: validation for use in clinical and postal research. J Pain 2005;6:149-58.

[3] Beurskens AJ, de Vet HC, Koke AJ. Responsiveness of functional status in low back pain: a comparison of different instruments. PAIN 1996;65: 71-6.

[4] Clark DB, Jones BL, Wood DS, Cornelius JR. Substance use disorder trajectory classes: diachronic integration of onset age, severity, and course. Addict Behav 2006;31:995-1009.

[5] Collins L, Lanza S. Latent class and latent transition analysis: with applications in the social, behavioural, and health sciences. New York: John Wiley \& Sons, 2010.

[6] Costa Lda C, Koes BW, Pransky G, Borkan J, Maher CG, Smeets RJ. Primary care research priorities in low back pain: an update. Spine (Phila Pa 1976) 2013;38:148-56.

[7] Downie AS, Hancock MJ, Rzewuska M, Williams CM, Lin CW, Maher CG. Trajectories of acute low back pain: a latent class growth analysis. PAIN 2016;157:225-34.

[8] Dunn KM, Croft PR. The importance of symptom duration in determining prognosis. PAIN 2006;121:126-32.

[9] Dunn KM, Jordan KP, Croft PR. Recall of medication use, self-care activities and pain intensity: a comparison of daily diaries and self-report questionnaires among low back pain patients. Prim Health Care Res 2010;11:93-102.

[10] EuroQuol Group. EuroQol-a new facility for the measurement of healthrelated quality of life. Health Policy 1990;16:199-208.

[11] Foster NE, Hill JC, O'Sullivan P, Hancock M. Stratified models of care. Best Pract Res Clin Rheumatol 2013;27:649-61.

[12] Fritz JM, Lindsay W, Matheson JW, Brennan GP, Hunter SJ, Moffit SD, Swalberg A, Rodriquez B. Is there a subgroup of patients with low back pain likely to benefit from mechanical traction? Results of a randomized clinical trial and subgrouping analysis. Spine (Phila Pa 1976) 2007;32: E793-800.

[13] Green DJ, Jordan KP, Protheroe J, van der Windt D. Development of hand phenotypes and changes in hand pain and problems over time in older people. PAIN 2016;157:569-76.

[14] Grotle M, Brox JI, Veierod MB, Glomsrod B, Lonn JH, Vollestad NK. Clinical course and prognostic factors in acute low back pain: patients consulting primary care for the first time. Spine (Phila Pa 1976) 2005; 3098:976-82.

[15] Hill JC, Dunn KM, Lewis M, Mullis R, Main CJ, Foster NE, Hay EM. A primary care back pain screening tool: identifying patient subgroups for initial treatment. Arthritis Rheum 2008;59:632-41.

[16] Hill JC, Konstantinou K, Egbewale BE, Dunn KM, Lewis M, van der Windt D. Clinical outcomes among low back pain consulters with referred leg pain in primary care. Spine (Phila Pa 1976) 2011;36: 2168-75.

[17] Kongsted A, Kent P, Albert H, Jensen TS, Manniche C. Patients with low back pain differ from those who also have leg pain or signs of nerve root involvement - a cross-sectional study. BMC Musculoskelet Disord 2012; 13:236.

[18] Kongsted A, Kent P, Hestbaek L, Vach W. Patients with low back pain had distinct clinical course patterns that were typically neither complete recovery nor constant pain. A latent class analysis of longitudinal data. Spine J 2015;15:885-94.
[19] Kongsted A, Kent P, Jensen TS, Albert H, Manniche C. Prognostic implications of the Quebec Task Force classification of back-related leg pain: an analysis of longitudinal routine clinical data. BMC Musculoskelet Disord 2013;14:171.

[20] Konstantinou K, Beardmore R, Dunn KM, Lewis M, Hider SL, Sanders T, Jowett S, Somerville S, Stynes S, van der Windt DA, Vogel S, Hay EM. Clinical course, characteristics and prognostic indicators in patients presenting with back and leg pain in primary care. The ATLAS study protocol. BMC Musculoskelet Disord 2012;13:4.

[21] Konstantinou K, Dunn KM, Ogollah R, Vogel S, Hay EM; ATLAS study research team. Characteristics of patients with low back and leg pain seeking treatment in primary care: baseline results from the ATLAS cohort study. BMC Musculoskelet Disord 2015;16:332-015.

[22] Konstantinou K, Hider SL, Vogel S, Beardmore R, Somerville S. Development of an assessment schedule for patients with low backassociated leg pain in primary care: a Delphi consensus study. Eur Spine J 2012;21:1241-9.

[23] Lacey RJ, Lewis M, Jordan K, Jinks C, Sim J. Interrater reliability of scoring of pain drawings in a self-report health survey. Spine (Phila Pa 1976) 2005;30:E455-458.

[24] Lamb SE, Lall R, Hansen Z, Castelnuovo E, Withers EJ, Nichols V, Griffiths F, Potter R, Szczepura A, Underwood M. A multicentred randomised controlled trial of a primary care-based cognitive behavioural programme for low back pain. The Back Skills Training (BeST) trial. Health Technol Assess 2010;14:1-253.

[25] Lee J, Gupta S, Price C, Baranowski AP, British Pain S. Low back and radicular pain: a pathway for care developed by the British Pain Society. Br J Anaesth 2013;111:112-20.

[26] Lewis R, Williams N, Matar HE, Din N, Fitzsimmons D, Phillips C, Jones M, Sutton A, Burton K, Nafees S, Hendry M, Rickard I, Chakraverty R, Wilkinson C. The clinical effectiveness and cost-effectiveness of management strategies for sciatica: systematic review and economic model. Health Technol Assess 2011;15:1-578.

[27] Miranda H, Viikari-Juntura E, Martikainen R, Takala EP, Riihimaki H. Individual factors, occupational loading, and physical exercise as predictors of sciatic pain. Spine (Phila Pa 1976) 2002;27:1102-9.

[28] Muthen B. Latent variable analysis: growth mixture modelling and related techniques for longitudinal data. In: Kaplan D, editor. Handbook of quantitative methodology for the social sciences. Newbury Park: Sage, 2004.

[29] NICE. Low back pain and sciatica in over 16s: assessment and management. London, 2016. https://www.nice.org.uk/guidance/ng59

[30] Nicholas MK. The pain self-efficacy questionnaire: taking pain into account. Eur J Pain 2007;11:153-63.

[31] Nylund KL, Asparouhov T, Muthén BO. Deciding on the number of classes in latent class analysis and growth mixture modeling: a Monte Carlo simulation study. Struct Equ Model 2007;14:535-69.

[32] Patrick DL, Deyo RA, Atlas SJ, Singer DE, Chapin A, Keller RB. Assessing health-related quality of life in patients with sciatica. Spine (Phila Pa 1976) 1995;20:1899-908.

[33] Peul WC, van Houwelingen HC, van den Hout WB, Brand R, Eekhof JA, Tans JT, Thomeer RT, Koes BW. Leiden-The Hague Spine Intervention Prognostic Study Group. Surgery versus prolonged conservative treatment for sciatica. N Engl J Med 2007;356:2245-56.

[34] Qaseem A, Wilt TJ, McLean RM, Forciea M. Clinical Guidelines Committee of the American College of Physicians. Noninvasive treatments for acute, subacute, and chronic low back pain: a clinical practice guideline from the American College of Physicians. Ann Int Med 2017; 166:514-30.

[35] Roland M, Morris R. A study of the natural history of back pain: part I: development of a reliable and sensitive measure of disability in low-back pain. Spine (Phila Pa 1976) 1983;8:141-4.

[36] Schafer A, Hall T, Briffa K. Classification of low back-related leg pain-A proposed patho-mechanism-based approach. Man Ther 2009;14:222-31.

[37] Spitzer W, LeBlanc FE, Dupuis M. Scientific approach to the assessment and management of activity related spinal disorders. A monograph for clinicians. Report of the Quebec Task Force on Spinal Disorders. Spine (Phila Pa 1976) 1987;12:S1-S59.

[38] Stynes S, Konstantinou K, Dunn KM. Classification of patients with low back-related leg pain: a systematic review. BMC Musculoskelet Disord 2016;17:226.

[39] Stynes S, Konstantinou K, Dunn KM, Lewis M, Hay EM. Reliability among clinicians diagnosing low back-related leg pain. Eur Spine J 2016;25: 2734-40.

[40] Taylor W, Gladman D, Helliwell P, Marchesoni A, Mease P, Mielants H. Classification criteria for psoriatic arthritis: development of new criteria from a large international study. Arthritis Rheum 2006;54:2665-73.

[41] Tubach F, Beauté J, Leclerc A. Natural history and prognostic indicators of sciatica. J Clin Epidemiol 2004;57:174-9. 
[42] Ware JE Jr. SF-36 health survey update. Spine (Phila Pa 1976) 2000;25: 3130.

[43] Wolfe F, Smythe HA, Yunus MB, Bennett RM, Bombardier C, Goldenberg DL, Tugwell P, Campbell SM, Abeles M, Clark P, Fam A, Farber S, Fiechtner J, Franklin M, GAtter R, Hamaty D, Lessard J, Lichtbroun A, Masi A, Mccain G, Reynolds J, Romano T, Russell J, Sheon R. The American College of Rheumatology 1990 criteria for the classification of fibromyalgia. Arthritis Rheum 1990;33:160-72.
[44] Wurpts IC, Geiser C. Is adding more indicators to a latent class analysis beneficial or detrimental? Results of a Monte-Carlo study. Front Psychol 2014;5:920.

[45] Yang CC. Evaluating latent class analysis models in qualitative phenotype identification. Comput Stat Data Anal 2006;50: 1090-104.

[46] Zigmond AS, Snaith RP. The hospital anxiety and depression scale. Acta Psychiatr Scand 1983;67:361-70. 